\title{
高周波電力を重畳した直流反応性スパッ夕法による $\mathrm{TaAl}-\mathrm{N}$ 薄膜の作製
}

岡野夕紀子*1. 田尻 修一 $* 1$. 青園 隆司*1. 岡本 昭夫*2.

$$
\text { 小川 倉一 } * 3 \cdot \text { 美馬 宏司*4 }
$$

\section{TaAl-N Thin Film Prepared by Radio Frequency and Direct Current Reactive Sputtering Yukiko OKANO*1, Shuichi TAJIRI*1, Takashi AOZONO*1, Akio OKAMOTO*2, Soichi OGAWA*3 and Hiroshi MIMA*3 \\ *1Okano Works, Ltd., 16-8 Taima-cho, Neyagawa, Osaka, 572-0078 \\ *2Technology Research Institute of Osaka Prefecture, 2-7-1 Ayumino, Izumi, Osaka, 594-1157 \\ *3Ogawa Creation Research Laboratory, 7-18-7 Kariguchidai, Tarumi, Kobe, 655-0049 \\ ${ }^{*}$ Osaka City University, 3-3-138 Sugimoto, Sumiyoshi, Osaka, 558-8585}

(Received November 15, 2007, Accepted February 9, 2008)

\begin{abstract}
The electrical characteristics of TaAl-N thin films prepared by radio frequency (RF) superimposed and direct current (DC) reactive sputtering method was investigated. The properties of TaAl-N thin films were strongly influenced by the sputtering method. In the condition of $\mathrm{Rn}=30 \%[\mathrm{Rn}=\mathrm{F}(\mathrm{N} 2) /(\mathrm{F}(\mathrm{N} 2)+\mathrm{F}(\mathrm{Ar}))]$, total pressure $0.3 \mathrm{~Pa}$, the resistivity (at $\mathrm{RT}$ ) was $3.1 \Omega \mathrm{cm}$ and the TCR $\left(\right.$ at $150^{\circ} \mathrm{C}$ ) (the temperature coefficient of the resistivity) was $(-) 13000 \mathrm{ppm} /{ }^{\circ} \mathrm{C}$. The stresses of $\mathrm{TaAl}-\mathrm{N}$ thin films were relieved.
\end{abstract}

\section{1.はじめに}

筆者らは, 反応性プラズマスパッタ法により作製した抵抗 温度係数（以下 TCR と記す）の大きなセンサ材料, TaAl$\mathrm{N}$ 薄膜を開発した ${ }^{1)}$ 。この材料を熱伝導型真空度センサとし て用いることで, 従来型のピラニセンサより広領域測定が可 能な熱伝導型真空計実用化の可能性を見出した ${ }^{2-4)}$. また, TaAl-N 薄膜における TCR の更なる向上のため, 成膜時の 窒素分圧比についても検討している5).

一方，反応性プラズマスパッタ法においては，成膜時の反 跳粒子や 2 次電子などの比較的高いエネルギー粒子の衝撃 により，薄膜内に格子不整が生じることによる格子欠陷や膜 応力が発生する. それらを軽減させるために, 通常では高温 での薄膜形成や，薄膜形成後に熱処理等の手段を講じる.し かし，高分子フィルム上に薄膜を形成する場合は，使用する 基板材料によって耐熱温度の制約があるため, 全て低温プロ セスで薄膜を形成する必要がある. そこで, 薄膜内に格子不 整を生じさせる原因である高エネルギ一粒子の発生を抑制す る方法として, 成膜時のターゲット電圧を高周波 $(\mathrm{RF})$ 電 力の重畳により低減し, スパッタ電力を変えずにターゲット 電圧のみを低下させた低エネルギーでの成膜プロセスの可能 性について検討した。

\section{2. 実験方法}

$\mathrm{Ta}$ と $\mathrm{Al}$ の面積比を $8: 2$ とした金属ターゲットを用い て，反応性スパッタ法により $\mathrm{TaAl}-\mathrm{N}$ 薄膜を作製した。窒 素流量比 $\mathrm{F}(\mathrm{N} 2) /(\mathrm{F}(\mathrm{N} 2)+\mathrm{F}(\mathrm{Ar}))$ （以下 Rn と記す）を 5

* 平成19年11月15日 第48回真空に関する連合講演会で発表

*1 侏岡野製作所（二572-0078 寝屋川市太間町16-8)

*2 大阪府立産業技術総合研究所（干594-1157 和泉市あゆ久野 2$7-1)$

*3 小川創造技術研究所（二655-0049 神戸市垂水区狩口台 7-187)

*4 大阪市立大学（=558-8585 大阪市住吉区杉本 3-3-138）

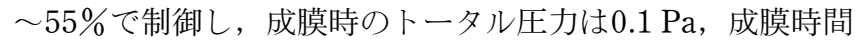
は25 minとした。

今までの検討結果から，直流 (DC) 電力のみを用いて $200 \mathrm{~W}$ の条件で成膜する場合， ターゲット電压は550 V と なる，そこで， $\mathrm{RF}$ 電力を $50 \mathrm{~W}$ 重畳することにより，ター ゲット電圧を $350 \mathrm{~V}$ に低減できた.

さらなる低電圧化をはかるため, 成膜時のトータル圧力を $0.1 \mathrm{~Pa}$ から $0.3 \mathrm{~Pa}$ へ変更して成膜を行った. トータル圧 力0.3 $\mathrm{Pa}$ に拈いては, $\mathrm{DC}$ 電力のみを用いて $200 \mathrm{~W}$ の条件で 成膜する場合, ターゲット電圧は $550 \mathrm{~V}$ から $430 \mathrm{~V}$ へと低減 したため, RF 電力を重畳することによりターゲット電圧は $350 \mathrm{~V}$ から $300 \mathrm{~V}$ へとさらに低電圧化させることができた.

Table 1 に成膜条件を示す.

得られた TaAl-N 薄膜の物性評価として，基板にコーニ ング7059ガラスを用いて作製した試料にて成膜速度，比抵 抗, 抵抗温度特性を評価し, TCR を算出した. 薄膜の結晶 状態をX 線回折分析により確認した。 また, 厚みが $25 \mu \mathrm{m}$ ポリイミドフィルム上に $14 \times 12 \mathrm{~mm}$ のサイズで TaAl-N 薄 膜を形成し, 膜部分のフィルムの変形から応力の状態を観察 した.

Table 1 Deposition condition of the TaAl-N thin film

\begin{tabular}{c|c}
\hline \hline Sputtering method & $\begin{array}{c}\text { The reacted DC magnetron } \\
\text { sputtering method }\end{array}$ \\
\hline DC Target voltage & $300 \sim 350 \mathrm{~V}$ \\
\hline RF power & $50 \mathrm{~W}$ \\
\hline Rn & $0 \sim 55 \%$ \\
\hline Temperature of substrate & $\mathrm{RT}$ \\
\hline Total pressure & $1.0 \times 10^{-1} \sim 3.0 \times 10^{-1} \mathrm{~Pa}$ \\
\hline Sputter time & $25 \mathrm{~min}$ \\
\hline
\end{tabular}




\section{3. 結果と検討}

\section{1 成膜速度と比抵抗}

Table. 2 に DC 電力と RF 電力を重畳した場合と従来の方 法である DC 電力のみを使用した場合の成膜速度および比抵 抗を示す. $\mathrm{Rn}=55 \%$ の場合, 従来の方法と比較して成膜速 度は $1 / 2$ 以下となり，比抵抗は大幅に高くなった． DC 電力 と $\mathrm{RF}$ 電力を重畳させた場合は, $\mathrm{Rn}$ が減少すると成膜速度 は増加し， $30 \%$ の場合には $10.0 \mathrm{~nm} / \mathrm{min}$ となった。一方， 比抵抗は低下し， $40 \%$ の場合は $1.1 \Omega \mathrm{cm}$ となり, 従来の方法 での比抵抗と同程度となった. 成膜速度と比抵抗の結果から, $\mathrm{RF}$ 電力を重畳させることにより成膜速度が低下し, 膜中の 窒化が促進されたと考えられる．このことは RF 電力の重畳 によってプラズマ密度が増加し, 同時に活性種の増大, すな わちより多くの窒素分子が励起されたことによる窒化反応の 促進を示している.

次に成膜時のトータル圧力を $0.1 \mathrm{~Pa}$ から $0.3 \mathrm{~Pa}$ へ変化さ せ, ターゲット電圧を $300 \mathrm{~V}$ と低減して成膜を行った.

Table 3 にRn と成膜速度および比抵抗の関係を示す. 同程 度の比抵抗を得るために Rn は $40 \%$ から $30 \%$ へ変化させる 必要があった。 また，この時の成膜速度は $5.9 \mathrm{~nm} / \mathrm{min}$ とな り, トータル圧力 $0.1 \mathrm{~Pa}$ の場合よりも成膜速度が低下した.

\section{2 抵抗温度特性}

トータル圧力を $0.1 \mathrm{~Pa}$ として DC 電力に RF 電力を重畳し

Table 2 Rn dependence of Deposition rate and Resitivity. (Total pressure : $0.1 \mathrm{~Pa}$ )

\begin{tabular}{|c|c|c|c|c|}
\hline $\begin{array}{l}\text { Sputterting } \\
\text { method }\end{array}$ & $\begin{array}{c}\text { Total } \\
\text { pressure } \\
{[\mathrm{Pa}]}\end{array}$ & $\begin{array}{l}\mathrm{Rn} \\
{[\%]}\end{array}$ & $\begin{array}{l}\text { Dep. rate } \\
{[\mathrm{nm} / \mathrm{min}]}\end{array}$ & $\begin{array}{l}\text { Resistivity } \\
{[\Omega \mathrm{cm}]}\end{array}$ \\
\hline \multirow{6}{*}{$\begin{array}{l}\text { DC power } \\
+\mathrm{RF} \text { power }\end{array}$} & \multirow{7}{*}{0.1} & 30 & 10.0 & $5.9 \times 10^{-2}$ \\
\hline & & 35 & 9.2 & $1.6 \times 10^{-2}$ \\
\hline & & 40 & 8.5 & 1.1 \\
\hline & & 45 & 8.0 & $2.2 \times 10^{1}$ \\
\hline & & 50 & 7.0 & $6.1 \times 10^{4}$ \\
\hline & & 55 & 5.0 & $6.1 \times 10^{4}$ \\
\hline DC power & & 55 & 12.3 & 2.1 \\
\hline
\end{tabular}

Table 3 Rn dependence of Deposition rate and Resitivity. (Total pressure : $0.3 \mathrm{~Pa}$ )

\begin{tabular}{l|c|c|c|c}
\hline \hline \multirow{2}{*}{ Sputterting method } & $\begin{array}{c}\text { Total } \\
\text { pressure } \\
{[\mathrm{Pa}]}\end{array}$ & $\begin{array}{c}\mathrm{Rn} \\
{[\%]}\end{array}$ & $\begin{array}{c}\text { Dep. rate } \\
{[\mathrm{nm} / \mathrm{min}]}\end{array}$ & $\begin{array}{c}\text { Resistivity } \\
{[\Omega \mathrm{cm}]}\end{array}$ \\
\hline \multirow{5}{*}{$\begin{array}{l}\text { DC power } \\
\text { + RF power }\end{array}$} & 5 & 10.5 & $2.2 \times 10^{-4}$ \\
\cline { 3 - 5 } & \multirow{2}{*}{0.3} & 10 & 8.1 & $5.2 \times 10^{-4}$ \\
\cline { 3 - 5 } & & 20 & 8.6 & $1.2 \times 10^{-1}$ \\
\cline { 3 - 5 } & & 25 & 6.4 & $1.8 \times 10^{-1}$ \\
\cline { 3 - 5 } & & 30 & 5.9 & 3.1 \\
\cline { 3 - 5 } & & 40 & 5.2 & $1.0 \times 10^{-2}$ \\
\hline
\end{tabular}

た $\mathrm{Rn}=40 \%$ に作製したサンプルにおいて，室温から500 ${ }^{\circ} \mathrm{C}$ をでの抵抗温度特性を測定し，TCR を算出した．Fig. 1 に結果を示す.

$150^{\circ} \mathrm{C}$ における TCR は $(-) 13000 \mathrm{ppm} /{ }^{\circ} \mathrm{C}$ となり従来の ものとほぼ同程度の值が得られた

\section{$3.3 \mathrm{X}$ 線回折分析}

トータル圧力が $0.1 \mathrm{~Pa}$ において作製した比抵抗が同程度 のサンプルにおいて X 線回折分析により結晶状態を確認し た. Fig. 2 に結果を示す.

重畳により, $60^{\circ}$ 近辺の $\mathrm{TaN}(220)$ のピークが消失し, $35^{\circ}$ 近辺の $\mathrm{TaN}(111)$ のピークも小さくなった.このことか ら， RF 電力を重畳することにより薄膜内部の結晶方向が (111)軸に揃い, さらに結晶粒径の微小化が考えられる.

\section{$3.4 \mathrm{TaAl}-\mathrm{N}$ 薄膜によるポリイミドフィルムの変形}

Fig. 3 に TaAl-N 薄膜によるポリイミドフィルムの変形 の様子について示す。 また, Table 4 に成膜条件と定性的に 求めた曲率半径を示す.

従来の成膜方法では, ポリイミドフィルムが大きく変形し た. 曲率半径は 5〜 $8 \mathrm{~mm}$ であった． $\mathrm{RF}$ 電力を重畳すると 変形は低減が見られ，曲率半径は $8 \sim 10 \mathrm{~mm}$ となった。し かし, トータル時の圧力を $0.3 \mathrm{~Pa}$ のサンプルにおいてはフ ィルムの変形の程度は減少しており, 曲率半径は $12 \sim 15$ $\mathrm{mm}$ であった．このことから従来の方法と比べて膜応力が大 きく低減したことがわかった。

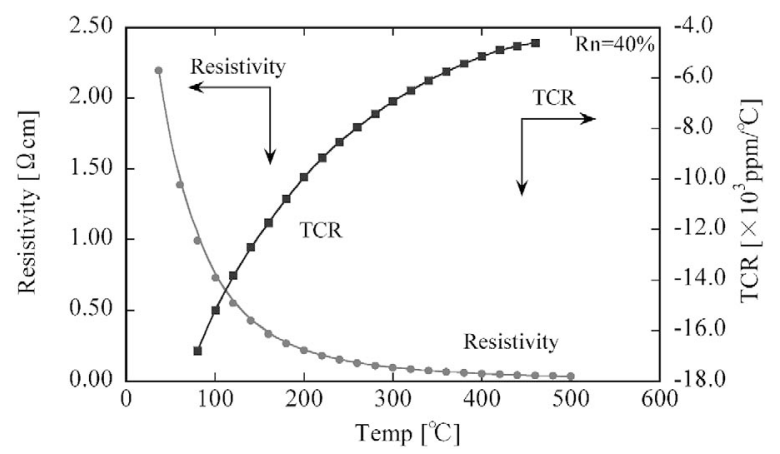

Fig. 1 Temperature dependence of Resistivity.

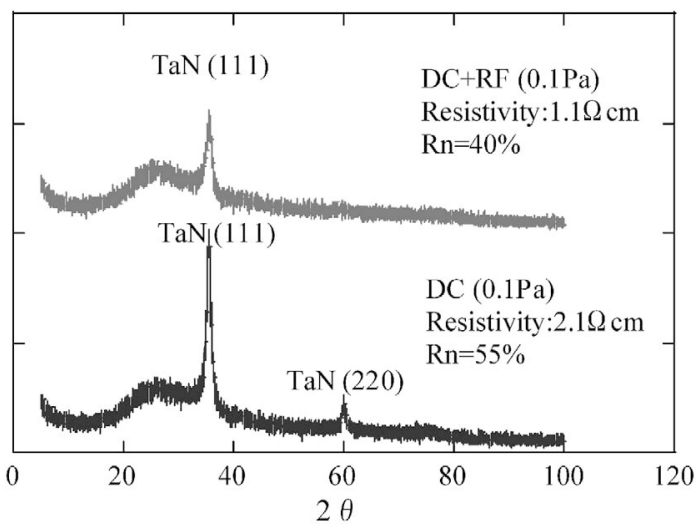

Fig. 2 XRD chart of TaAl-N. 


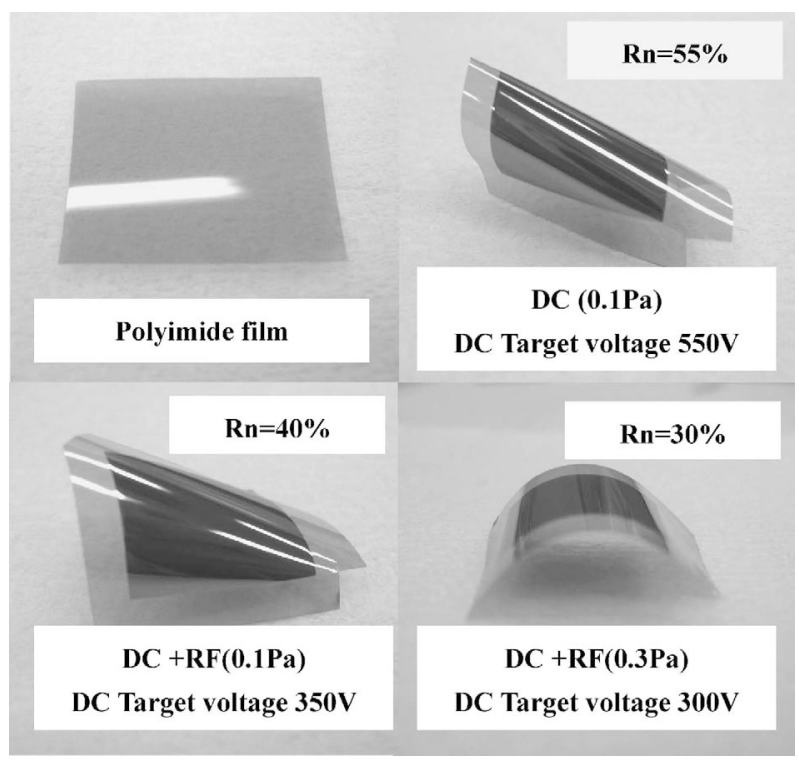

Fig. 3 TaAl-N thin film on Polyimide film.

Table 4 Curvature radius of TaAl-N thin film on polyimide film

\begin{tabular}{c|c}
\hline \hline Deposition condition & $\begin{array}{c}\text { Curvature radius } \\
{[\mathrm{mm}]}\end{array}$ \\
\hline $\begin{array}{c}\text { DC }(0.1 \mathrm{~Pa}) \\
\text { DC Target voltage }: 550 \mathrm{~V}\end{array}$ & $5-8$ \\
\hline $\begin{array}{c}\text { DC }+\mathrm{RF}(0.1 \mathrm{~Pa}) \\
\text { DC Target voltage }: 350 \mathrm{~V}\end{array}$ & $8-10$ \\
\hline $\begin{array}{c}\text { DC }+\mathrm{RF}(0.3 \mathrm{~Pa}) \\
\text { DC Target voltage }: 300 \mathrm{~V}\end{array}$ & $12-15$ \\
\hline
\end{tabular}

\section{4. まと め}

反応性スパッタ法による $\mathrm{TaAl}-\mathrm{N}$ 薄膜の作製において, $\mathrm{RF}$ 電力の重畳により成膜時のターゲット電圧を低減し，低 ダメージの成膜方法を検討したところ，次のことが判明した.

1. $\mathrm{DC}$ 電力に $\mathrm{RF}$ 電力を $50 \mathrm{~W}$ 重畳させることにより， ス パッタ電力を変化させずにターゲット電圧のみを低減するこ とが可能であることが確かめられた。

2. $\mathrm{DC}$ 電力と $\mathrm{RF}$ 電力を重畳させることにより， $\mathrm{Rn}=55 \%$
の場合は従来の方法と比較して成膜速度が $1 / 2$ 以下とな り，比抵抗は大幅に高くなった. Rn が減少すると成膜速度 は増加し， $30 \%$ の場合には $10.0 \mathrm{~nm} / \mathrm{min}$ となった。一方， $\mathrm{Rn}$ が減少すると比抵抗は低下し, $\mathrm{Rn}=40 \%$ の場合は 1.1 $\Omega \mathrm{cm}$ となり, 従来の方法で成膜した場合の比抵抗と同程度 であった。

3. 成膜時のトータル圧力を $0.1 \mathrm{~Pa}$ から $0.3 \mathrm{~Pa}$ へ変化させた 場合，同程度の比抵抗を得るために Rn は $40 \%$ から $30 \%$ へ 変化させる必要があった。 また，この時の成膜速度は 5.9 $\mathrm{nm} / \mathrm{min}$ であった。

4. $\mathrm{DC}$ 電力と $\mathrm{RF}$ 電力を重畳させた $\mathrm{Rn}=40 \%$ のンプル に颃いて，室温から $500^{\circ} \mathrm{C}$ までの抵抗温度特性を測定して TCR を算出したところ, $150^{\circ} \mathrm{C}$ における TCR は $(-) 13000$ $\mathrm{ppm} /{ }^{\circ} \mathrm{C}$ となり従来の方法で成膜した場合とほぼ同程度の值 が得られた。

5. $\mathrm{X}$ 線回折分析より, $\mathrm{DC}$ 電力と $\mathrm{RF}$ 電力を重畳させるこ とによって薄膜内部の結晶方向が (111) 軸に揃い, さらに結 晶粒径の微小化が見られた。

6. 成膜時のトータル圧力と $\mathrm{Rn}$ を最適化して同程度の比抵 抗が得られる条件に打いては，DC 電力のみで成膜する場合 よりも $\mathrm{RF}$ 電力を重畳させることにより, ポリイミドフィル ム上の膜応力が低減することが確かめられた。

以上の結果から, DC 電力に RF 電力を重畳して印加し, 成膜時のトータル圧力を増加させ, ターゲット電圧を低減し た条件においても，Rnを制御することにより従来と同程度 の特性を有し, 膜応力を低減した TaAl-N 薄膜の作製条件 を見出した.

\section{〔文献〕}

1）田尻修一, 青園隆司, 岡本昭夫, 小川倉一, 美馬宏司 : 第43回 真空に関する連合講演会予稿集 p. 279 (2002).

2) 田尻修一, 青園隆司, 岡本昭夫, 小川倉一, 美馬宏司 : 第44回 真空に関する連合講演会予稿集 p. 84 (2003).

3）田尻修一, 青園隆司, 岡本昭夫, 小川倉一, 美馬宏司 : 第45回 真空に関する連合講演会予稿集 p. 108 (2004).

4）岡野夕紀子, 田尻修一, 青園隆司, 岡本昭夫, 小川倉一, 美馬 宏司：Shinku 49 (2006) 162.

5）岡野夕紀子, 田尻修一, 青園隆司, 岡本昭夫, 小川倉一, 美馬 宏司：Shinku 50 (2007) 173. 